\title{
Regeneration of Leydig cells in ectopically autografted adult mouse testes
}

\author{
Himesh Makala, Lavanya Pothana, Surabhi Sonam, Ashwini Malla and Sandeep Goel \\ Laboratory for the Conservation of Endangered Species, Centre for Cellular and Molecular Biology, \\ Council for Scientific and Industrial Research, Uppal Road, Hyderabad 500 007, India \\ Correspondence should be addressed to S Goel; Email: sandeep@ccmb.res.in
}

\begin{abstract}
Ectopic autografting of testis tissue is a promising approach for studying testicular development, male germline preservation and restoration of male fertility. In this study, we examined the fate of various testicular cells in adult mouse testes following ectopic autografting at 1, 2, 4 and 8 weeks post grafting. Histological examination showed no evidence of re-establishment of spermatogenesis in autografts, and progressive degeneration of seminiferous tubules was detected. Expression of germ cell-specific proteins such as POU5F1, DAZL, TNP1, TNP2, PRM1 and PRM2 revealed that, although proliferating and differentiating spermatogenic germ cells such as spermatogonia, spermatocytes and spermatids could survive in autografts until 4 weeks, only terminally differentiated germ cells such as sperm persisted in autografts until 8 weeks. The presence of Sertoli and peritubular myoid cells, as indicated by expression of WT1 and ACTA2 proteins, respectively, was evident in the autografts until 8 weeks. Interestingly, seminal vesicle weight and serum testosterone level were restored in autografted mice by 8 weeks post grafting. The expression of Leydig cell-specific proteins such as CYP11 A1, HSD3B2 and LHCGR showed revival of Leydig cell (LC) populations in autografts over time since grafting. Elevated expression of PDGFRA, LIF, DHH and NEFH in autografts indicated de novo regeneration of LC populations. Autografted adult testis can be used as a model for investigating Leydig cell regeneration, steroidogenesis and regulation of the intrinsic factors involved in Leydig cell development. The success of this rodent model can have therapeutic applications for adult human males undergoing sterilizing cancer therapy. Reproduction (2015) 149 259-268
\end{abstract}

\section{Introduction}

Grafting of immature testicular tissue into immunodeficient mice is a successful strategy for growing immature testicular tissue and retrieving differentiated germ cells with fertilization capacity (Honaramooz et al. 2002). Successful generation of sperm from xenografts of immature testes from mice, hamsters, monkeys (Schlatt et al. 2002), bulls (Oatley et al. 2005), pigs, goats (Honaramooz et al. 2002), cats (Snedaker et al. 2004), buffaloes (Reddy et al. 2012) and mouse hosts has already been reported. Previous studies have shown that xenografted testis tissue from sexually mature donors is less successful than that from sexually immature donors (Arregui et al. 2008). Moreover, complete spermatogenesis has been reported to be absent in the xenografts that contained post-meiotic germ cells at the time of grafting in all species analyzed to date, and most of the mature donor grafts regressed or were found to contain degenerated tubules (Schlatt et al. 2002, 2006, Geens et al. 2006, Arregui et al. 2008, Abrishami et al. 2010). Spermatogenesis was arrested at meiosis in grafts from mature horse (Rathi et al. 2006), dog (Abrishami et al. 2010) and photoregressed hamster testes (Schlatt et al. 2002).
Survival of only seminiferous tubules with Sertoli cells was seen in mature bull and monkey donor grafts; however, complete spermatogenesis was observed when the donor graft tissue was not completely mature (Arregui et al. 2008). No germ cell differentiation was observed in adult human testes xenografted onto mouse hosts (Geens et al. 2006, Schlatt et al. 2006).

Testis cryopreservation and autografting offer a valuable option for restoring fertility in cancer patients who undergo cancer therapy that leads to subsequent sterilization. Testis autografting has been shown to be a feasible option for production of sperm in monkeys (Jahnukainen et al. 2012). However, autologous immature testis grafts in the marmoset matured to meiosis, but normal serum testosterone level was not restored (Wistuba et al. 2006). In addition, autologous transplantation of testis tissue to the greater omentum and abdominal wall without vascular anastomosis was not viable in rats (Nunes et al. 2013). The fate of testicular cells of adult mouse testes following ectopic autografting is so far unreported.

The objective of this study is to examine the fate of testicular germ and somatic cells in ectopically autografted adult mouse testes. Our results indicate that 
Leydig cells regenerated de novo in the autografted adult testes, restoring the serum testosterone level.

\section{Material and methods Testis tissue autografting}

All animal procedures were approved by the Institutional Animal Care and Use Committee (IACUC) of the Centre for Cellular and Molecular Biology (CCMB), Hyderabad, India. Adult Balb/c mice (10 weeks old; $n=27$ ) were anesthetized with ketamine $(0.1 \mathrm{mg} / \mathrm{kg}$ body weight $(B W))$ and xylazine $(0.5 \mathrm{mg} / \mathrm{kg} \mathrm{BW})$ in sterile physiological saline. The mice were castrated through a ventral medial incision in the abdomen and the testes were removed; subsequently, the peritoneum and skin were sutured closed using absorbable sutures (Ethicon, www.novartis.com). During the same surgery, each mouse received two incisions ( $\sim 5 \mathrm{~mm}$ ) on each side of the back (four incisions total). Each collected testis was weighed and then cut in half, and each half was inserted through each incision. The other testis was treated similarly. All four incision sites were sutured closed and the mice were then allowed to recover and returned to their cages.

\section{Recovery and analysis of autografts}

At 1, 2, 4 and 8 weeks post grafting, the mice were killed by $\mathrm{CO}_{2}$ inhalation. The grafts were recovered, weighed and fixed in Bouin's solution followed by three changes in $70 \%$ ethanol before being processed for histology. The testes from 10-weekold mice $(n=5)$ were also collected as the control and then fixed and processed for histology. After processing, the tissues were embedded in paraffin, sectioned ( $7 \mu \mathrm{m}$ thick), stained with haematoxylin and eosin (H\&E), dehydrated, mounted in Vectamount (Vector Laboratories, www.vectorlabs.com) and observed under a Zeiss Axioplan 2 microscope (Carl Zeiss AG, www.zeiss.de). The tubules that did not contain distinct cell types were considered to be degenerated. The grafts were classified as degenerated when no tubules were found and nondegenerated even if it contained a single seminiferous tubule with spermatogenesis. In grafts which had seminiferous tubules were observed, all tubules were analyzed and classified either as degenerated or non-degenerated.

The percentage of recovered grafts was calculated for all mice in which grafts were found, and it was also recorded when no grafts were recovered. The percentage of seminiferous tubules and degenerated tubules within a graft were also calculated.

\section{Autografted mouse analysis}

Seminal vesicles from all autografted mice were weighed for assessment of the bioactive circulating testosterone level (Honaramooz et al. 2002, Reddy et al. 2012). Blood was collected from autografted mice at the time when being killed by cardiac puncture, and serum was subsequently collected by centrifugation. Blood and average weight of seminal vesicles from intact age-matched male mice $(B a l b / c ; n=20,5$ mice for each collection time point) were taken as controls.
Serum samples were analyzed for testosterone concentration using a commercial kit (CAN-TE-250; Diagnostics Biochem Canada, Inc., www.dbc-labs.com).

\section{CYP11A1, HSD3B and PRM2 immunostaining of autografts}

The autografted testes sections were stained with cytochrome P450, family 11, subfamily A (CYP11A1) and hydroxy-delta-5steroid dehydrogenase, 3 beta- and steroid delta-isomerase 2 (HSD3B2) antibodies to examine the expression of Leydig cell-specific proteins. The autografts were also stained with protamine 2 (PRM2) antibody to confirm the existence of sperm. Adult testes were also stained as positive controls. Primary and secondary antibodies were prepared diluted in PBS with 1\% BSA (Sigma, www.sigmaaldrich.com). Briefly, after de-paraffinization and rehydration, the sections were blocked with $10 \%$ foetal bovine serum (Gibco, www. invitrogen.com) and 3\% BSA in PBS for $30 \mathrm{~min}$; incubated with rabbit anti-CYP11A1 (1: 100; Millipore, www.millipore. com), goat anti-HSD3B2 (1:30) or goat anti-PRM2 antibody (1:20; both from Santa Cruz Biotechnology, Inc., www.scbt. com) overnight at $4{ }^{\circ} \mathrm{C}$; washed several times with PBS; incubated with $3 \% \mathrm{H}_{2} \mathrm{O}_{2}$ for $10 \mathrm{~min}$; washed three times with PBS, incubated with goat anti-rabbit or rabbit anti-goat HRP-conjugated secondary antibody (1:200; Calbiochem, www.calbiochem.com) for $30 \mathrm{~min}$ at $37^{\circ} \mathrm{C}$, rinsed three times with PBS, incubated for 3-5 min in DAB Substrate Kit (Vector Laboratories) according to the manufacturer's instructions, rinsed thoroughly in distilled water; and mounted. For negative controls, the rabbit/goat isotype control antibodies (Santa Cruz Biotechnology, Inc.) were used instead of primary antibodies at the same concentration, but all other procedures remained the same.

\section{Western blotting analysis of autografts}

Total proteins from the autografts were extracted upon homogenization by sonication in a dissolving buffer $(7 \mathrm{M}$ urea, $2 \mathrm{M}$ thiourea, 4\% CHAPS, $18 \mathrm{mM}$ Tris-HCl, $14 \mathrm{mM}$ TrisBase, $0.2 \%$ Triton- $X$ and $50 \mathrm{mM}$ dithiothreitol). Single-strength ProteCEASE-50, EDTA-free protease inhibitor (G-Biosciences, www.gbiosciences.com) was added to the dissolving buffer before protein extraction. The lysed samples $(50 \mu \mathrm{g})$ were subjected to electrophoresis in 12\% SDS-polyacrylamide gel. The gels were transferred onto PVDF membranes (Millipore). The membranes were blocked with Starting Block (TBS) blocking buffer (Thermo Scientific, www.piercenet.com) for $1 \mathrm{~h}$ at room temperature. The blocked membranes were incubated with one of the following primary antibodies: proliferating cell nuclear antigen (PCNA; 1:1000) or CYP11A1 (1:1000) from Millipore; deleted in azoospermialike (DAZL; 1:5000); leukemia inhibitory factor (LIF; 1:1000); desert hedgehog (DHH; 1:10 000); neurofilament, heavy polypeptide (NEFH; 1:10 000); POU class 5 homeobox 1 (POU5F1; 1:1000) or glyceraldehyde-3-phosphate dehydrogenase (GAPDH; 1:1000) from Thermo Scientific; and actin, alpha 2, smooth muscle (ACTA2; 1:10 000); luteinizing hormone/choriogonadotrophin receptor (LHCGR; 1:200); 
HSD3B2 (1:200); platelet-derived growth factor receptor-a (PDGFRA; 1:400); Wilms tumour 1 (WT1; 1:200); transition nuclear protein 1 (TNP1; 1:200); transition nuclear protein 2 (TNP2; 1:200) or PRM1 (1:200) from Santa Cruz Biotechnology, Inc. The membranes were then washed with TBSTand incubated with goat anti-rabbit, goat anti-mouse or rabbit anti-goat HRP-conjugated secondary antibody (1:10 000; both from Thermo Scientific) in TBS-T for $1 \mathrm{~h}$ at room temperature. After washing with TBS-T, immunoreactivity was detected by chemoluminescence using a C-DiGit Blot Scanner (LI-COR Biosciences, www.licor.com) against SuperSignal West Femto chemiluminescent substrate (Thermo Scientific), and the generated signal was analyzed using a densitometer. To control protein loading on the gels, the membranes were further probed with GAPDH antibody.

\section{Statistical analyses}

The results are presented as mean \pm s.E.M. The statistical analyses were performed by ANOVA. Significant differences between the means were determined by analyzing the data using the Fisher's Protected Least Significant Difference (PLSD) test. The level of significance was set at $P<0.05$. In all figures, data are presented as mean \pm S.E.M. Bars with asterisks $\left(^{*}\right)$ and bars with different letters are significantly different.

\section{Results}

\section{Grafts recovery, graft weight and histological analysis}

The autografted testicular tissues were identified and recovered from the dorsal skin at various time points. Although the recovery of grafts until 4 weeks post grafting was not significantly different (Table $1 ; P>0.05$ ), the recovery at 8 weeks was significantly reduced $(P<0.05)$.

Testis autografts were weighed at each collection time point to assess the proliferation of testicular somatic cells and progression of spermatogenesis. Average graft weight did not significantly differ before grafting (T0) and 1 and 2 weeks post grafting (Fig. $1 \mathrm{~A} ; P>0.05$ ). However, the weight of grafts collected at 4 and 8 weeks was significantly lower than that at T0 as well as at 1 and 2 weeks post grafting $(P<0.05)$. The weight of grafts collected at 4 weeks was higher than that at

Table 1 Experimental autograft data.

\begin{tabular}{lccc}
\hline $\begin{array}{l}\text { Graft } \\
\text { period } \\
\text { (weeks) }\end{array}$ & $\begin{array}{c}\text { No. of mice } \\
\text { autografted } \\
\text { and analysed }\end{array}$ & $\begin{array}{c}\text { No. of } \\
\text { autografts } \\
\text { recovered }^{\mathrm{a}}(\%)\end{array}$ & $\begin{array}{c}\text { No. of autografts with } \\
\text { non-degenerated } \\
\text { tubules }^{\mathrm{b}}(\%)\end{array}$ \\
\hline 1 & 7 & $100(28 / 28)^{\mathrm{A}}$ & $3.5(1 / 28)$ \\
2 & 6 & $95.8(23 / 24)^{\mathrm{A}}$ & $0(23 / 23)$ \\
4 & 7 & $96.4(27 / 28)^{\mathrm{A}}$ & $0(27 / 27)$ \\
8 & 7 & $75.0(21 / 28)^{\mathrm{B}}$ & $0(21 / 21)$ \\
\hline
\end{tabular}

Different superscript letters (A and B) indicate significant difference within the column $(P<0.05)$.

${ }^{a}$ Total grafts removed divided by the total number of grafts grafted.

${ }^{b}$ Percentage of recovered grafts with intact seminiferous tubules.
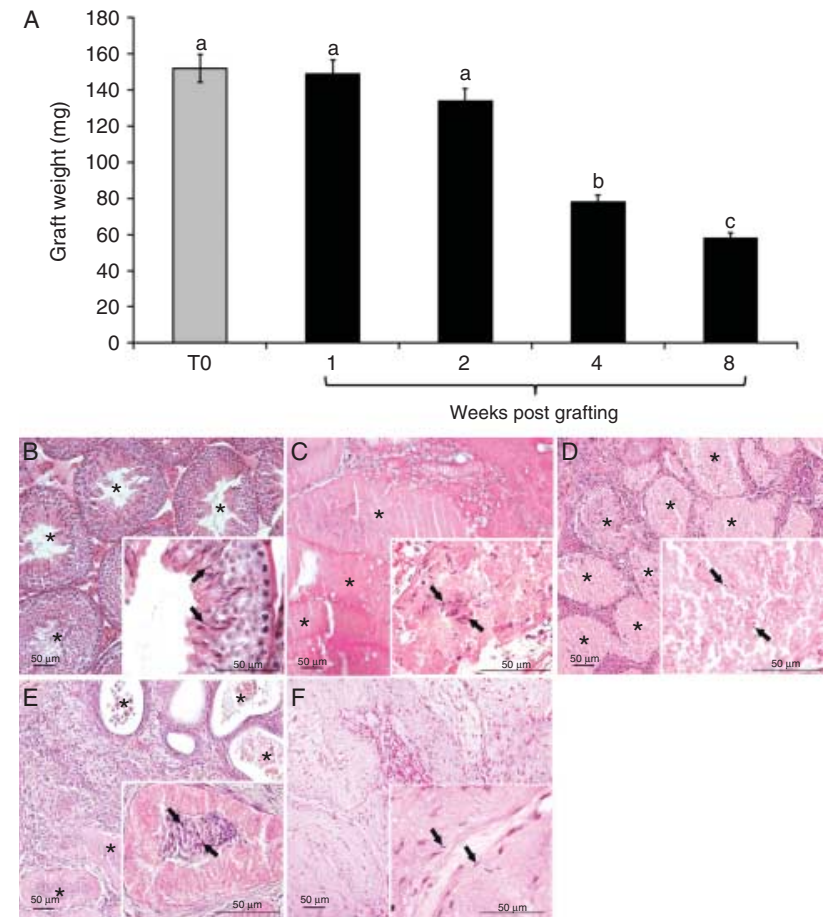

Figure 1 Graft weights and histological evaluation of grafts. (A) Average weight of autografted testis tissue showed significant reduction at 4 and 8 weeks post grafting. T0, testicular weight before grafting as a representation of starting material. Haematoxylin and eosin staining of (B) 10-week-old testis tissue before grafting and (C) 1 week, (D) 2 weeks, (E) 4 weeks and (F) 8 weeks post grafting. Note the progressive degeneration of seminiferous tubules $\left(^{*}\right)$ in the grafts over time since grafting. At 8 weeks post grafting, no visible tubules are observed. Insets show magnified region of a section in which sperm are indicated by arrows. Data represent mean \pm S.E.M. Bars with different letters are significantly different at $P<0.05$. Scale bar $=50 \mu \mathrm{m}$.

8 weeks, but this difference was not statistically significant $(P>0.05)$.

Histological evaluation of 10 -week-old mice testes showed intact seminiferous tubules with spermatogenesis in $98.9 \%$ of tubules (Fig. 1B). A prominent lumen was present in seminiferous tubules, and spermatozoa were the most advanced germ cells. Histological examination of graft tissues showed varying degrees of tubular degeneration during the grafting period. Grafts collected at 1 week contained almost all degenerated tubules (Fig. 1C); however, in one graft, a few intact tubules $(12.4 \%)$ were detected (Table 1$)$. In grafts collected at 2 weeks, greater degenerative changes were evident in the tubules (Fig. 1D). In grafts collected at 4 weeks (Fig. 1E), degeneration was extensive with loss of most tubules and at 8 weeks, no intact tubules were observed in the autografts (Fig. 1F). The autografts showed progressive loss of sperm cells with increase in collection time. At 8 weeks, a few sperm could be detected in $0.2-0.5 \%$ of degenerated tubules (Fig. 1F). 


\section{Serum testosterone and seminal vesicle weight}

The serum testosterone level of grafted mice until 4 weeks was significantly lower than that of agematched control mice (Fig. 2A; $P<0.05$ ). At 8 weeks, the serum testosterone level of grafted mice was similar to that of age-matched controls $(P>0.05)$. Similarly, the average weight of seminal vesicles recovered from grafted mice until 4 weeks was significantly lower than that from age-matched control mice (Fig. 2B; $P<0.05$ ). At 8 weeks, average weight of seminal vesicles of grafted mice did not differ from that of age-matched controls $(P>0.05)$.

\section{CYP11A1, HSD3B2 and PRM2 immunostaining of autografts}

Immunohistochemical analysis with the Leydig cell-specific markers CYP11A1 and HSD3B2 facilitated identification of Leydig cells in grafts (Fig. 3). The steroidogenic enzymes CYP11A1 and HSD3B2 showed restricted immunolocalization in the Leydig cells and were present as well-defined clusters in the interstitial space of the 10-week-old mouse testes (Fig. 3A and G). The CYP11A1 and HSD3B2 staining was localized in the cytoplasm of stained cells. Fewer cells were positive for CYP11A1 and HSD3B2 in the grafts collected at 1 week
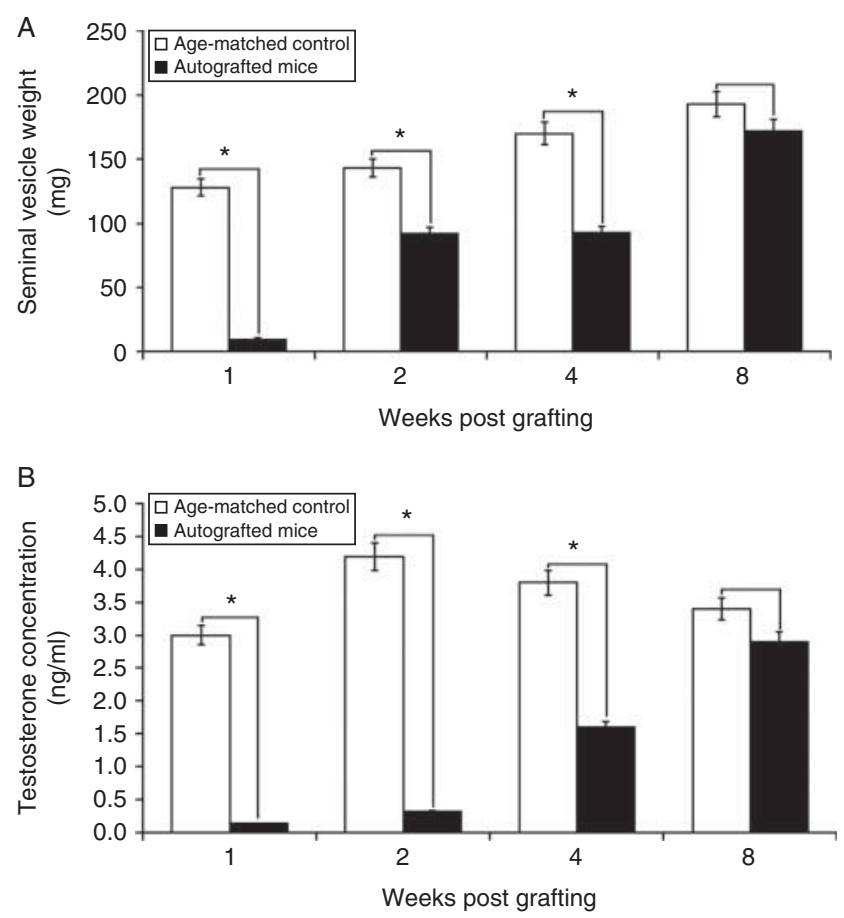

Figure 2 (A) Seminal vesicle weights and (B) serum testosterone autografted recipients and age-matched control mice at 1, 2, 4 and 8 weeks post grafting. Note that the seminal vesicle weight and serum testosterone are significantly lower in autografted mice than that in agematched control mice at all collection time points except at 8 weeks post grafting. Data represent mean \pm S.E.M. $\left({ }^{*} P<0.05\right)$.

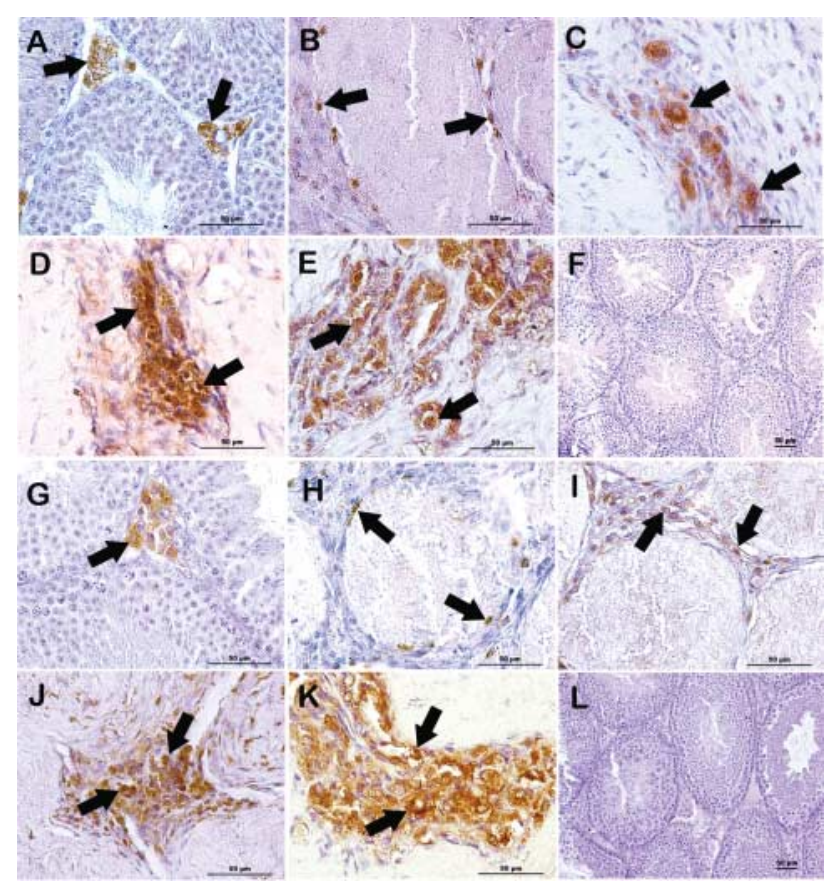

Figure 3 Identification of Leydig cells in autografts by expression of the Leydig cell-specific proteins (A, B, C, D, E and F) CYP11A1 and (G, H, I, $\mathrm{J}, \mathrm{K}$ and L) HSD3B2. Stained cells are indicated by arrows. Both markers showed Leydig cell-specific staining in 10-week-old mouse testis tissue, (A) CYP11A1 and (G) HSD3B2. Fewer Leydig cells were found in grafts collected at 1 week ( $\mathrm{B}$ and $\mathrm{H})$ and 2 weeks ( $\mathrm{C}$ and $\mathrm{I})$. At 4 weeks ( $\mathrm{D}$ and $\mathrm{J}$ ) and 8 weeks ( $\mathrm{E}$ and $\mathrm{K}$ ) post grafting, Leydig cells are abundantly present in the grafts. Note that the staining intensity of both markers progressively increased with increase in graft collection time. In negative controls ( $\mathrm{F}$ and $\mathrm{L}$ ), where primary antibodies were omitted and sections were incubated with isotype control antibodies, no positive cells are present. Scale bar $=50 \mu \mathrm{m}$.

and the stained cells were localized in peritubular region (Fig. 3B and H). However, CYP11A1- and HSD3B2positive cells progressively increased in the grafts collected at 2 weeks (Fig. 3C and I), 4 weeks (Fig. 3D and J) and 8 weeks (Fig. 3E and K). Interestingly, the staining intensity for CYP11A1 was stronger than that for HSD3B2 in the sections at all collection times. No CYP11A1- and HSD3B2-positive cells were present in negative control sections, in which the isotype control antibodies were used instead of primary antibodies (Fig. 3F and L).

The presence of sperm in autografts was evaluated by PRM2 immunostaining. PRM2 staining in 10 -week-old mouse testis sections was detected in elongated spermatids and sperm (Fig. 4A). In autografts collected at 1 week (Fig. 4B), 2 weeks (Fig. 4C) and 4 weeks (Fig. 4D), PRM2-positive cells could be identified in $50-85 \%$ of the degenerated tubules. In the autografts collected at 8 weeks, PRM2-positive sperm were detected in $1-2 \%$ of the degenerated tubules (Fig. 4E). Most PRM2-positive sperm appeared fragmented as indicated by their smaller size. In negative control sections in which isotopic control antibody was 


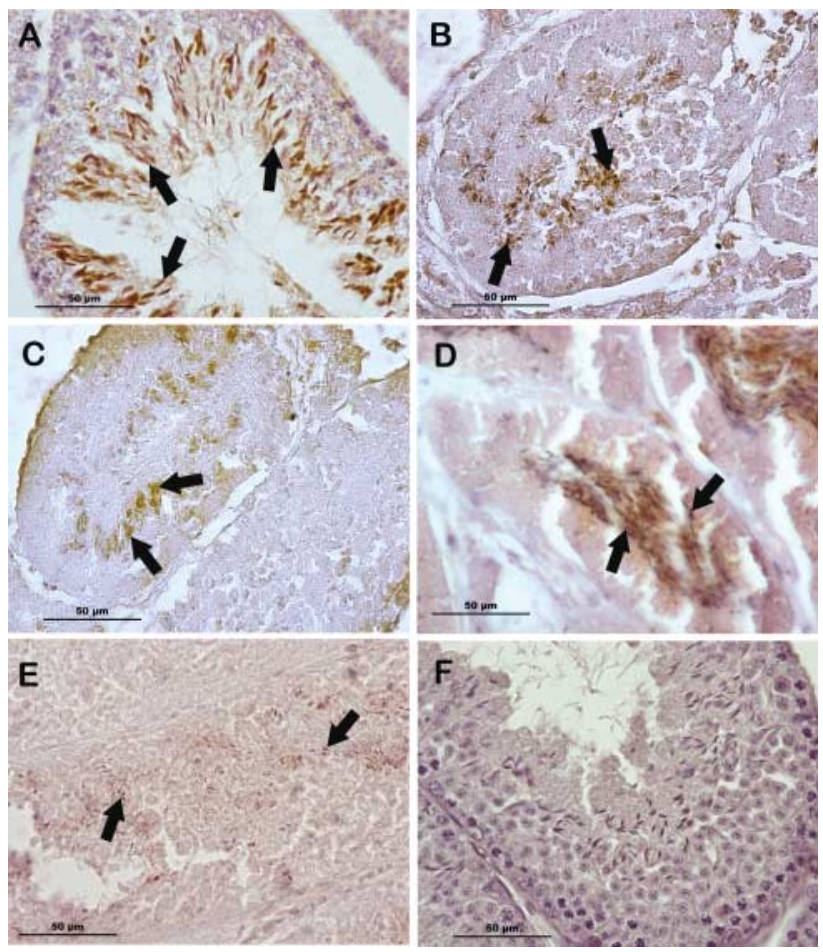

Figure 4 Immunostaining of autografts with PRM2 antibody for identifying sperm. PRM2-positive cells are indicated by arrows. (A) PRM2-positive elongated spermatids and sperm in a 10-week-old mouse testis section. In autografts collected at (B) 1 week, (C) 2 weeks and (D) 4 weeks post grafting, PRM2-positive sperm can be seen in the degenerated tubules. In grafts collected 8 weeks post grafting (E), many fragmented sperm that are PRM2-positive can be seen. In negative control (F), where primary antibody was omitted and section was incubated with an isotype control antibody, no positive cells are present. Scale bar $=50 \mu \mathrm{m}$.

used instead of primary antibody, no PRM2-positive cells were present (Fig. 4F).

\section{Western blotting analysis of autografts}

The expression of several testicular cell-specific and Leydig cell regeneration signalling-specific proteins was analyzed in the grafted testes at each collection time point by western blot analysis (Fig. 5A). The expression levels of the Leydig cell-specific proteins CYP11A1, HSD3B2 and LHCGR progressively increased with increased collection time of grafts (Fig. 5B). The expression levels of CYP11A1, HSD3B2 and LHCGR proteins were significantly higher in grafts collected at 2 and 4 weeks than in those collected at 1 week (Fig. 5B, $P<0.05)$. Interestingly, CYP11A1, HSD3B2 and LHCGR expression increased to 35-, five- and 3.5-fold respectively, in grafts collected at 8 weeks $(P<0.05)$. The expression of cell proliferation-specific protein PCNA level was elevated in grafts collected at 1 week (Fig. 5B). Thereafter, PCNA expression level gradually decreased in grafts with increase in collection time and was lowest at 8 weeks $(P<0.05)$. The expression of PDGFRA, a stem Leydig cell (SLC)-specific protein, was elevated in grafts at 1 week, reached its peak level at 2 weeks and thereafter, and progressively declined at 4 and 8 weeks (Fig. 5C; $P<0.05$ ). Interestingly, PDGFRA expression was absent from adult testes. Similar to PDGFRA, NEFH expression was raised elevated in grafts collected at 1 week, peaked at 2 weeks, and then a significant gradual decrease was observed at 4 and 8 weeks (Fig. 5C; $P<0.05$ ). Like PDGFRA, NEFH expression was absent in adult testes. The expression of $\mathrm{DHH}$ protein was elevated in grafts collected at 1 week and reached its peak level at 2 weeks (Fig. 5C; $P<0.05$ ). Thereafter, DHH expression significantly lowered in grafts collected at 4 and 8 weeks $(P<0.05)$. The expression of LIF protein was high in grafts collected at 1 week, declined twofold at 2 weeks, and was absent from grafts collected at 4 and 8 weeks (Fig. 5C; $P<0.05$ ). The expression of the Sertoli cell-specific protein WT1 progressively increased in grafts over time since grafting (Fig. 5D; $P<0.05$ ). The expression of the ACTA2 protein was present in grafts collected at 1 week, peaked significantly in grafts collected at 2 weeks, and thereafter declined in autografts collected at 4 and 8 weeks (Fig. 5D; $P<0.05$ ). The expression of the germ cellspecific proteins POU5F1, DAZL, TNP1 and TNP2 was present in grafts collected at 1, 2 and 4 weeks (Fig. 5E). However, at 8 weeks, their expression was absent from grafts (Fig. 5E; $P<0.05$ ). Interestingly, POU5F1 protein expression level showed a twofold increase in grafts collected at 4 weeks compared with autografts collected at 1 and 2 weeks $(P<0.05)$. The expression level of PRM1 protein was low at 1 week and significantly raised in grafts collected at 2, 4 and 8 weeks (Fig. 5E; $P<0.05$ ).

\section{Discussion}

This study explores the fate of various cell types in adult testes following ectopic autografting. A significant number of grafts were recovered until 1, 2 and 4 weeks post grafting. However at 8 weeks, the number of recovered grafts was significantly reduced. The weight of collected grafts was also found to be significantly declined at 4 and 8 weeks. Histological examination of grafts showed a progressive disintegration of the testicular architecture and extensive degeneration of seminiferous tubules as time since grafting increased.

Degeneration of graft testicular tissue could have possibly occurred because of the absence of the natural scrotal environment and exposure to hyperthermic conditions at the ectopic site of grafting. The adult testes of species with high daily sperm production such as pig and goat after xenografting to mice recipients showed a complete degeneration of tubules and grafts (Arregui et al. 2008). However in species such as bull and monkeys where daily sperm production is low, xenografted adult testes had either degenerated tubules or 

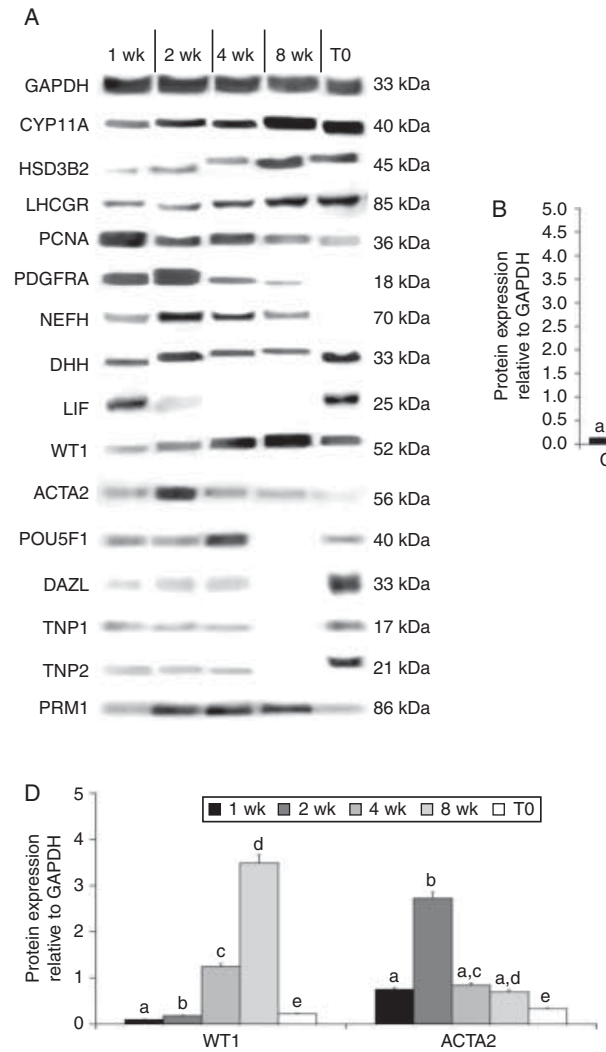
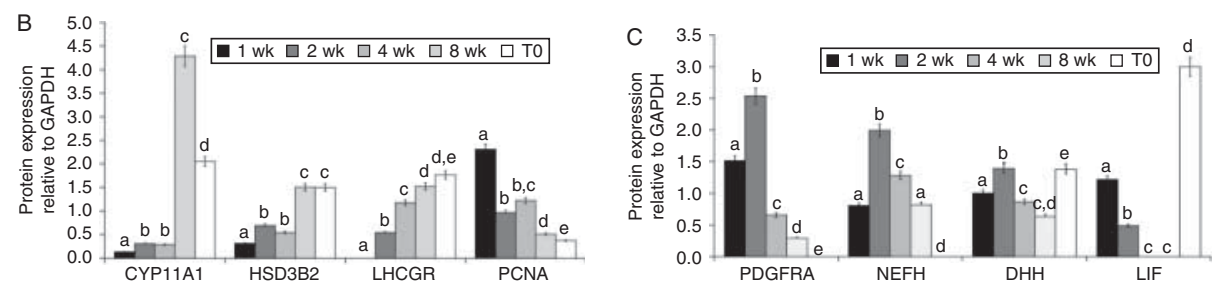

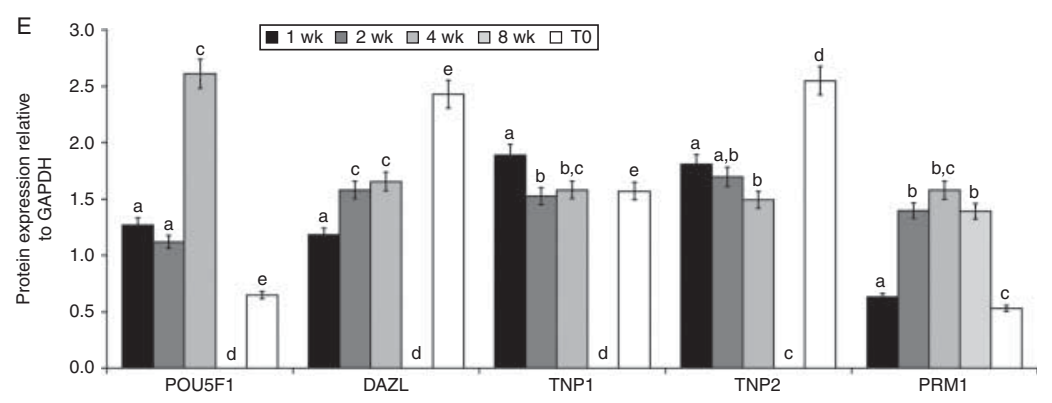

Figure 5 Expression of Leydig cell-, germ cell-, Sertoli cell- and cell signalling-specific proteins in autografted testes at 1, 2, 4 and 8 weeks post grafting by western blotting analysis. T0, protein expression in 10-week-old mice before grafting as a representation of starting material.

Representative western blotting (A) and densitometry analysis of CYP11A1, HSD3B2, LHCGR and PCNA (B), PDGFRA, NEFH, DHH and LIF (C), WT1 and ACTA2 (D), POU5F1, DAZL, TNP1, TNP2 and PRM1 (E). Data represent mean \pm s.E.M. Bars with different letters are significantly different for a given protein at $P<0.05$.

tubules that contained only Sertoli cells (Arregui et al. 2008). In rare cases, tubules with spermatogonia without meiotic spermatogenic cells were also present. Degenerated tubules or tubules that contained only Sertoli cells were also observed in adult human testis (in which, daily sperm production is low) after xenografting (Geens et al. 2006). As mice testis also has efficient spermatogenesis with high sperm production, extensive degeneration of autografts was expected in this study. The adult testis tissue grafts are also highly sensitive to ischaemia (Schlatt et al. 2002) and have a high demand for oxygen because of ongoing spermatogenesis (Schlatt et al. 2010). Ischaemic conditions could have contributed to extensive degeneration of grafts that led to significant loss in graft weight and complete atrophy of several grafts that may have affected their recovery. These findings are consistent with those of previous studies, which reported regression of adult grafts or extensive sclerosis following ectopic xenografting (Schlatt et al. 2002, 2006, Geens et al. 2006, Arregui et al. 2008). Seminiferous tubules with complete spermatogenesis were only detected in one graft, which was collected at 1 week. This rare graft could have survived the initial period of hypoxia, leading to the persistence of seminiferous tubules with spermatogenesis. However, by 2 weeks and thereafter, seminiferous tubules could not be detected in any graft. Therefore, we conclude that spermatogenesis cannot be revived in ectopically autografted adult testes.

As the grafted testes showed extensive degeneration, it was difficult to identify testicular cells. Therefore, to evaluate the existence of various testicular cell types in grafts, expression of several testicular cell-specific proteins was examined by western blotting analysis. The presence of Sertoli cells in the grafts was ascertained by the expression of a transcription factor, WT1. WT1 expression in Sertoli cells is initiated early in foetal life and continues thereafter, and it is primarily localized to the nucleus throughout all phases of life (Mackay 2000). WT1 is localized in Sertoli cells in both embryonic (Gao et al. 2006) and adult mice (Sridharan et al. 2007). WT1 protein expression showed progressive increase in grafts over time since grafting. This could be due to degeneration of other testicular cell types in autografts that may have led to net increase in the amount of proteins of surviving Sertoli cells. Nonetheless, this indicates that Sertoli cells were rather resilient to ischaemic damages induced as a result of ectopic grafting. Surprisingly, Sertoli cells survived despite 
extensive degeneration of seminiferous tubules in the autografted testes. This finding is in agreement with earlier studies which reported that Sertoli cells could be detected in xenografts following extensive degeneration and sclerosis of seminiferous tubules (Schlatt et al. 2006, Arregui et al. 2008). It remains elusive and therefore requires further validation to determine whether the Sertoli cells survived or originated de novo in the grafts.

ACTA2 protein expression could be detected in grafts at all collection time points; however, it was significantly higher at 2 weeks. ACTA2 is expressed by the peritubular myoid cells and vascular tissues in testes. Peritubular myoid cells not only provide structural integrity to the tubule but also take part in the regulation of spermatogenesis and testicular function (Maekawa et al. 1996). Several studies have found that Leydig cells are generated by transdifferentiation of pericytes (PCs)/ vascular smooth muscle cells (VSMCs), as determined by morphological and immunohistological analyses (Davidoff et al. 2004, 2009). The presence of CYP11A1 and HSD3B2-positive cells in peritubular location in autografts collected at 1 week in this study supports previous findings. ACTA2 is co-expressed in nestinpositive PCs/VSMCs and freshly regenerated Leydig cells after experimentally induced Leydig cell elimination in adult animals (Davidoff et al. 2004). The high expression of ACTA2 at 2 weeks is suggestive of perivascular origin of Leydig cells in the grafts.

The presence of germ cells in grafts was evaluated by examining proteins expressed at different stages of germ cell differentiation. Although expression of POU5F1, DAZL, TNP1 and TNP2 proteins was present in grafts collected at 1, 2 and 4 weeks, their expression was absent at 8 weeks. Only the expression of PRM1 was present in grafts collected at all-time points. The expression of POU5F1 in postnatal mouse testes is restricted to spermatogonial stem cells (SSCs; Imamura et al. 2006, Western et al. 2010). DAZL is expressed in spermatogonia, spermatocytes and round as well as elongated spermatids (Reijo et al. 2000). The protein TNP1 and TNP2 belongs to nuclear transition protein family (Yelick et al. 1991), and these are expressed in round and elongated spermatids (Wykes et al. 1995, Adham et al. 2001).

PRM1 and PRM2 are arginine-rich proteins synthesized in late-stage spermatids (Balhorn 2007), and thus have been used as markers for spermatid differentiation (Lee et al. 1995, Zhao et al. 2004). The transition proteins or histones are replaced by PRM in mature sperm nuclei (Balhorn et al. 1984, Lewis et al. 2004). The results from this study indicate that proliferating and differentiating spermatogenic germ cells, such as spermatogonia, spermatocytes, as well as round and elongated spermatids, are sensitive to ischaemic insults and are not able to survive until 8 weeks in grafted testes. However, terminally differentiated germ cells such as sperm survived until 8 weeks as indicated by PRM1 and
PRM2 protein expression in autografts. This corroborates the results of an earlier report in which sperm were observed in otherwise completely sclerotic tubules and without the presence of other spermatogenic cells in adult mouse testes that were grafted onto nude mice (Geens et al. 2006). Although sperm were observed in very few tubules in sections that were stained with $\mathrm{H} \& \mathrm{E}$, a higher number of tubules had PRM2-stained cells in autografts collected at 8 weeks post grafting. This could be because PRM2 immunostaining is more sensitive to the presence of sperm. The stained sperm appear fragmented due to extensive degeneration of tubules. This suggests that, despite extensive degeneration of seminiferous tubules, some sperm can still survive and some sperm-specific proteins are expressed in autografts at 8 weeks post grafting. However, it remains unclear as to how the sperm survived in grafts in which there is complete degeneration of seminiferous tubules.

A consistent increase in the serum testosterone level and seminal vesicle weight was observed in autografted mice with increased time since grafting onto the host; however, they differed from the age-matched control until 4 weeks. At 8 weeks, serum testosterone level and seminal vesicle weight of grafted mice were not different from that of the age-matched control. This indicates that, by 8 weeks, autografted testes were able to produce sufficient testosterone to restore normal serum level and seminal vesicle weight, which are similar to the results of the age-matched control mice. The results from earlier studies in rodents showed restoration of seminal vesicle weight in mice (Boyle et al. 1975) and serum testosterone level in rats (Miragem et al. 2009) following testis autografting, which are consistent with the findings if this study. Although serum testosterone level and seminal vesicle weight of autografted mice were restored by 8 weeks, it remains unclear whether this was due to survival of Leydig cell populations in ectopically autografted testes or de novo regeneration of Leydig cells.

Despite extensive degeneration of seminiferous tubules in grafts, the presence of interstitial cells was evident. Although there were very few steroidogenic enzyme-specific protein-expressing cells (e.g. CYP11A1 and HSD3B2) in grafts at 1 week, their number increased as collection time increased post grafting. CYP11A1 and HSD3B2 are Leydig cell-specific markers in mouse testes (Davidoff et al. 2004). The western blotting analysis also substantiates the loss of Leydig cell populations in autografts at 1 week. Testosterone level and seminal vesicle weight until 4 weeks were significantly lower than that of the age-matched controls. These findings indicate degeneration of the original Leydig cell population in grafts after ectopic transplantation because of the hypoxic damage during the ischaemic period immediately following grafting. Interestingly, translation of cell-signalling proteins pertaining to Leydig cell regeneration was significantly higher in grafts collected at 1 and 2 weeks. 
PDGFRA is reported to be expressed in foetal and neonatal rat testes of SLC populations (Ge et al. 2006). Its expression level was significantly higher in grafts collected at 1 and 2 weeks, but showed a significant decline thereafter. PDGFRA and its ligand, plateletderived growth factor-a (PDGFA) are required for development of Leydig cell (Ge et al. 2006). In PDGFRA-null mice, differentiation of foetal Leydig cells is disrupted (Brennan et al. 2003). The expression of PDGFRA in autografts indicates the presence of SLC/ progenitor populations that may have contributed to Leydig cell regeneration in a manner similar to that reported in rats following ethane dimethanesulfonate (EDS) treatment (Davidoff et al. 2004, O'Shaughnessy et al. 2008).

$\mathrm{DHH}$ expression was present in grafts at all collection time points; however, a surge in expression was observed at 2 weeks. $\mathrm{DHH}$ is a cell signalling molecule produced by Sertoli cells, and disruption of spermatogenesis and loss of adult-type Leydig cells are reported in $\mathrm{DHH}$-null mice (Clark et al. 2000, Pierucci-Alves et al. 2001, Yao et al. 2002). DHH signalling triggers Leydig cell differentiation by upregulation of CYP11A1 expression because it acts as a positive regulator of steroidproducing Leydig cell differentiation from foetal to adult testes (Yao et al. 2002). In the absence of DHH and PDGFA, adult Leydig cells (ALCs) fail to develop, which can also be related to the failure of stem cell development (Clark et al. 2000, Gnessi et al. 2000, Park et al. 2007). However, high translation of $\mathrm{DHH}$ and PDGFRA proteins at 2 weeks in grafts indicates an abundance of SLCs.

LIF, a pleiotropic cytokine produced predominantly by the peritubular myoid cells of the seminiferous tubules (Dorval-Coiffec et al. 2005) is expressed in Sertoli cells and spermatogonia (Piquet-Pellorce et al. 2000). LIF and PDGFA stimulate SLC proliferation (Arregui et al. 2008). Interestingly, LIF expression peaked at 1 week, whereas PDGFRA expression peaked at 2 weeks in this study. It is therefore likely that LIF and PDGFA signalling in SLCs occurs at different time points; moreover, LIF withdrawal stimulates embryonic stem cell differentiation (Ward et al. 2004). The absence of LIF in grafts at 4 and 8 weeks indicates SLC differentiation. As we did not examine expression of the LIF receptor, it is possible that LIF activity may have persisted at later time points in the grafts. As LIF is known to control the proliferation and survival of SSCs, including primordial germ cells and gonocytes (De Felici \& Dolci 1991, Pesce et al. 1993, Piquet-Pellorce et al. 2000), the absence of LIF expression in grafts at 4 and 8 weeks could be an indication SSC loss. A recent study has shown that selective inhibition of PDGFR signalling in human mesenchymal stem cells leads to upregulation of POU5F1 and NANOG expression (Ball et al. 2012). In this study, PDGFRA expression showed an inverse correlation with POU5F1 expression in grafts. A similar signalling pathway could possibly be involved in the regeneration of Leydig cells in autografted testis.

LH stimulates testosterone synthesis in Leydig cells by binding to specific, high-affinity receptors (LHCGR) that are present on the surface of Leydig cells (Dufau 1988). LHCGR protein expression progressively increased in grafts over time since grafting, which is a pattern similar to CYP11A1 and HSD3B2 protein expression in this study. LHCGR receptor signalling is essential for Leydig cell differentiation (Teerds et al. 2007) and Leydig progenitor cells (LPCs) possess very few LH receptors (Shan \& Hardy 1992). The lowered expression of LHCGR in grafts collected at 1 and 2 weeks indicates the existence of LPCs. Progressive increase in LHCGR expression in grafts with increasing collection time demonstrates increased tropic stimulation of the developing Leydig cells.

NEFH is a type IV intermediate filament protein that is expressed in the neuronal/glial lineage (Doetsch 2003). LPCs begin to express not only steroidogenic enzymes such as CYP11A1, but also a number of neuronal antigens including NEFH (Davidoff et al. 2009). Newly formed Leydig cells acquire neuroendocrine characteristics that are required for maturation of Leydig cells in adult testes (Middendorff et al. 1993, 1996, Bakalska et al. 2002, Davidoff et al. 2004). A weak expression of NEFH was present in grafts at 1 week in this study. Interestingly, NEFH expression peaked in grafts at 2 weeks and then declined at 4 and 8 weeks. These findings are consistent with those of an earlier report that revealed transient elevated expression of NEFH after EDS exposure in rats localized to the vascular Leydig cell progenitor, which coincided with their transition from proliferative to transformation activity (Davidoff et al. 2004). A similar signalling pathway in autografted testes may be involved, although this idea requires further validation.

PCNA is a cyclin protein that is expressed in proliferating cells (Almendral et al. 1987). In testes, PCNA expression is detected in the mitotically proliferating spermatogonia, but not in spermatocytes that have just entered meiosis (Chapman \& Wolgemuth 1994, Liang et al. 2001). In later stages of meiotic prophase, PCNA is again observed in spermatogenic cells, in particular the zygotene and pachytene spermatocytes (Chapman \& Wolgemuth 1994). In this study, autografted testes showed substantial degeneration of tubules. Therefore, proliferation of germ cells can be ruled out. The high expression of PCNA protein in the grafts at 1,2 and 4 weeks could be due to the presence of proliferating SLCs and PLCs, which have high mitotic activities. The decline in PCNA expression in autografts collected at 8 weeks indicate the appearance of ALCs, which do not usually proliferate (Keeney et al. 1988).

In conclusion, ectopically autografted adult testes undergo extensive degeneration with loss of spermatogenic cells, but terminally differentiated germ cells, such 
as spermatozoa, survive. Peritubular myoid and Sertoli cells also survived in autografts. Leydig cells regenerated de novo, restoring the serum testosterone level and seminal vesicle weight in autografted mice. This study describes a novel model system for studying Leydig cell regeneration in mice. As mouse Leydig cells are resistant to the cytotoxic effect of EDS (Kerr et al. 1987), the testis autograft model system can be used for investigating Leydig cell regeneration, steroidogenesis and regulation of the intrinsic factors involved in Leydig cell development. This model could also provide insights into overcoming testosterone deficiency and Leydig cell dysfunction in vertebrate species.

\section{Declaration of interest}

The authors declare that there is no conflict of interest that could be perceived as prejudicing the impartiality of the research reported.

\section{Funding}

This work was supported by the Council for Scientific and Industrial Research (CSIR), Government of India (GOI) (grant number BSC0207) and Central Zoo Authority (CZA), GOI (grant number GAP0389).

\section{Author contribution statement}

H Makala, L Pothana, S Sonam and A Malla performed the research and analyzed the data; $\mathrm{S}$ Goel designed the research study and wrote the paper.

\section{Acknowledgements}

The authors would like to thank Mr Jedy Jose for his assistance with animal experiments.

\section{References}

Abrishami M, Abbasi S \& Honaramooz A 2010 The effect of donor age on progression of spermatogenesis in canine testicular tissue after xenografting into immunodeficient mice. Theriogenology 73 512-522. (doi:10.1016/j.theriogenology.2009.09.035)

Adham IM, Nayernia K, Burkhardt-Gottges E, Topaloglu O, Dixkens C, Holstein AF \& Engel W 2001 Teratozoospermia in mice lacking the transition protein 2 (Tnp2). Molecular Human Reproduction 7 513-520. (doi:10.1093/molehr/7.6.513)

Almendral JM, Huebsch D, Blundell PA, Macdonald-Bravo H \& Bravo R 1987 Cloning and sequence of the human nuclear protein cyclin: homology with DNA-binding proteins. PNAS 84 1575-1579. (doi:10.1073/pnas.84.6.1575)

Arregui L, Rathi R, Zeng W, Honaramooz A, Gomendio M, Roldan ER \& Dobrinski I 2008 Xenografting of adult mammalian testis tissue. Animal Reproduction Science 106 65-76. (doi:10.1016/j.anireprosci. 2007.03.026)

Bakalska M, Koeva I, Atanassova N, Angelova P, Nikolov B \& Davidoff M 2002 Steroidogenic and structural differentiation of new Leydig cell population following exposure of adult rats to ethane dimethanesulphonate. Folia Biologica 48 205-209.
Balhorn R 2007 The protamine family of sperm nuclear proteins. Genome Biology 8 227. (doi:10.1186/gb-2007-8-9-227)

Balhorn R, Weston S, Thomas C \& Wyrobek AJ 1984 DNA packaging in mouse spermatids. Synthesis of protamine variants and four transition proteins. Experimental Cell Research 150 298-308. (doi:10.1016/00144827(84)90572-X)

Ball SG, Shuttleworth A \& Kielty CM 2012 Inhibition of platelet-derived growth factor receptor signaling regulates Oct4 and Nanog expression, cell shape, and mesenchymal stem cell potency. Stem Cells 30 548-560. (doi:10.1002/stem.1015)

Boyle PF, Fox M \& Slater D 1975 Transplantation of interstitial cells of the testis: effect of implant site, graft mass and ischaemia. British Journal of Urology 47 891-898. (doi:10.1111/j.1464-410X.1975.tb04073.x)

Brennan J, Tilmann C \& Capel B 2003 Pdgfr- $\alpha$ mediates testis cord organization and fetal Leydig cell development in the XY gonad. Genes and Development 17 800-810. (doi:10.1101/gad.1052503)

Chapman DL \& Wolgemuth DJ 1994 Expression of proliferating cell nuclear antigen in the mouse germ line and surrounding somatic cells suggests both proliferation-dependent and -independent modes of function. International Journal of Developmental Biology 38 491-497.

Clark AM, Garland KK \& Russell LD 2000 Desert hedgehog (Dhh) gene is required in the mouse testis for formation of adult-type Leydig cells and normal development of peritubular cells and seminiferous tubules. Biology of Reproduction 63 1825-1838. (doi:10.1095/biolreprod63.6. 1825)

Davidoff MS, Middendorff R, Enikolopov G, Riethmacher D, Holstein AF \& Muller D 2004 Progenitor cells of the testosterone-producing Leydig cells revealed. Journal of Cell Biology 167 935-944. (doi:10.1083/jcb. 200409107)

Davidoff MS, Middendorff R, Muller D \& Holstein AF 2009 The neuroendocrine Leydig cells and their stem cell progenitors, the pericytes. Advances in Anatomy, Embryology, and Cell Biology 205 $1-107$.

De Felici M \& Dolci S 1991 Leukemia inhibitory factor sustains the survival of mouse primordial germ cells cultured on TM4 feeder layers. Developmental Biology 147 281-284. (doi:10.1016/S0012-1606(05) 80025-9)

Doetsch F 2003 The glial identity of neural stem cells. Nature Neuroscience 6 1127-1134. (doi:10.1038/nn1144)

Dorval-Coiffec I, Delcros JG, Hakovirta H, Toppari J, Jegou B \& PiquetPellorce C 2005 Identification of the leukemia inhibitory factor cell targets within the rat testis. Biology of Reproduction 72 602-611. (doi:10.1095/biolreprod.104.034892)

Dufau ML 1988 Endocrine regulation and communicating functions of the Leydig cell. Annual Review of Physiology 50 483-508. (doi:10.1146/ annurev.ph.50.030188.002411)

Gao F, Maiti S, Alam N, Zhang Z, Deng JM, Behringer RR, Lecureuil C, Guillou F \& Huff V 2006 The Wilms tumor gene, Wt1, is required for Sox 9 expression and maintenance of tubular architecture in the developing testis. PNAS 103 11987-11992. (doi:10.1073/pnas. 0600994103)

Ge RS, Dong Q, Sottas CM, Papadopoulos V, Zirkin BR \& Hardy MP 2006 In search of rat stem Leydig cells: identification, isolation, and lineagespecific development. PNAS 103 2719-2724. (doi:10.1073/pnas. 0507692103)

Geens M, De Block G, Goossens E, Frederickx V, Van Steirteghem A \& Tournaye H 2006 Spermatogonial survival after grafting human testicular tissue to immunodeficient mice. Human Reproduction 21 390-396. (doi:10.1093/humrep/dei412)

Gnessi L, Basciani S, Mariani S, Arizzi M, Spera G, Wang C, Bondjers C, Karlsson L \& Betsholtz C 2000 Leydig cell loss and spermatogenic arrest in platelet-derived growth factor (PDGF)-A-deficient mice. Journal of Cell Biology 149 1019-1026. (doi:10.1083/jcb.149.5.1019)

Honaramooz A, Snedaker A, Boiani M, Scholer H, Dobrinski I \& Schlatt S 2002 Sperm from neonatal mammalian testes grafted in mice. Nature 418 778-781. (doi:10.1038/nature00918)

Imamura M, Miura K, Iwabuchi K, Ichisaka T, Nakagawa M, Lee J, KanatsuShinohara M, Shinohara T \& Yamanaka S 2006 Transcriptional repression and DNA hypermethylation of a small set of ES cell marker genes in male germline stem cells. BMC Developmental Biology 634. (doi:10.1186/1471-213X-6-34) 
Jahnukainen K, Ehmcke J, Nurmio M \& Schlatt S 2012 Autologous ectopic grafting of cryopreserved testicular tissue preserves the fertility of prepubescent monkeys that receive sterilizing cytotoxic therapy. Cancer Research 72 5174-5178. (doi:10.1158/0008-5472.CAN-12-1317)

Keeney DS, Mendis-Handagama SM, Zirkin BR \& Ewing LL 1988 Effect of long term deprivation of luteinizing hormone on Leydig cell volume, Leydig cell number, and steroidogenic capacity of the rat testis. Endocrinology 123 2906-2915. (doi:10.1210/endo-123-6-2906)

Kerr JB, Knell CM, Abbott M \& Donachie K 1987 Ultrastructural analysis of the effect of ethane dimethanesulphonate on the testis of the rat, guinea pig, hamster and mouse. Cell and Tissue Research 249 451-457. (doi:10.1007/BF00215530)

Lee K, Haugen HS, Clegg CH \& Braun RE 1995 Premature translation of protamine $1 \mathrm{mRNA}$ causes precocious nuclear condensation and arrests spermatid differentiation in mice. PNAS 92 12451-12455. (doi:10.1073/ pnas.92.26.12451)

Lewis JD, Saperas N, Song Y, Zamora MJ, Chiva M \& Ausio J 2004 Histone $\mathrm{H} 1$ and the origin of protamines. PNAS 101 4148-4152. (doi:10.1073/ pnas.0308721101)

Liang JH, Sankai T, Yoshida T \& Yoshikawa Y 2001 Immunolocalization of proliferating cell nuclear antigen (PCNA) in cynomolgus monkey (Macaca fascicularis) testes during postnatal development. Journal of Medical Primatology 30 107-111. (doi:10.1034/j.1600-0684.2001. 300206.x)

Mackay S 2000 Gonadal development in mammals at the cellular and molecular levels. International Review of Cytology 200 47-99. (doi:10. 1016/S0074-7696(00)00002-4)

Maekawa M, Kamimura K \& Nagano T 1996 Peritubular myoid cells in the testis: their structure and function. Archives of Histology and Cytology $\mathbf{5 9}$ 1-13. (doi:10.1679/aohc.59.1)

Middendorff R, Davidoff M \& Holstein AF 1993 Neuroendocrine marker substances in human Leydig cells - changes by disturbances of testicular function. Andrologia 25 257-262. (doi:10.1111/j.1439-0272.1993. tb02722.x)

Middendorff R, Muller D, Paust HJ, Davidoff MS \& Mukhopadhyay AK 1996 Natriuretic peptides in the human testis: evidence for a potential role of C-type natriuretic peptide in Leydig cells. Journal of Clinical Endocrinology and Metabolism 81 4324-4328. (doi:10.1210/jcem.81. 12.8954035)

Miragem A, Neto BS, Reche M, Kliemann LM, Capp E \& von Eye Corleta H 2009 Subcutaneous autologous testicle transplantation in Wistar rats. International Urology and Nephrology 41 313-318. (doi:10.1007/ s11255-008-9465-1)

Nunes SI, Fernandes CB, Rezende DF, Bernardes JB \& Silva MV 2013 Verification of the feasibility of autogenous testis implant in omentum and abdominal wall in mice. Revista do Colégio Brasileiro de Cirurgõies 40 60-65. (doi:1590/S0100-69912013000100011)

Oatley JM, Reeves JJ \& McLean DJ 2005 Establishment of spermatogenesis in neonatal bovine testicular tissue following ectopic xenografting varies with donor age. Biology of Reproduction 72 358-364. (doi:10.1095/ biolreprod.104.030783)

O'Shaughnessy PJ, Morris ID \& Baker PJ 2008 Leydig cell re-generation and expression of cell signaling molecules in the germ cell-free testis. Reproduction 135 851-858. (doi:10.1530/REP-07-0529)

Park SY, Tong M \& Jameson JL 2007 Distinct roles for steroidogenic factor 1 and desert hedgehog pathways in fetal and adult Leydig cell development. Endocrinology 148 3704-3710. (doi:10.1210/en.20061731)

Pesce M, Farrace MG, Piacentini M, Dolci S \& De Felici M 1993 Stem cell factor and leukemia inhibitory factor promote primordial germ cell survival by suppressing programmed cell death (apoptosis). Development 118 1089-1094.

Pierucci-Alves F, Clark AM \& Russell LD 2001 A developmental study of the desert hedgehog-null mouse testis. Biology of Reproduction 65 1392-1402. (doi:10.1095/biolreprod65.5.1392)

Piquet-Pellorce C, Dorval-Coiffec I, Pham MD \& Jegou B 2000 Leukemia inhibitory factor expression and regulation within the testis. Endocrinology 141 1136-1141. (doi:10.1210/endo.141.3.7399)

Rathi R, Honaramooz A, Zeng W, Turner R \& Dobrinski I 2006 Germ cell development in equine testis tissue xenografted into mice. Reproduction 131 1091-1098. (doi:10.1530/rep.1.01101)
Reddy N, Mahla RS, Thathi R, Suman SK, Jose J \& Goel S 2012 Gonadal status of male recipient mice influences germ cell development in immature buffalo testis tissue xenograft. Reproduction 143 59-69. (doi:10.1530/REP-11-0286)

Reijo RA, Dorfman DM, Slee R, Renshaw AA, Loughlin KR, Cooke H \& Page DC 2000 DAZ family proteins exist throughout male germ cell development and transit from nucleus to cytoplasm at meiosis in humans and mice. Biology of Reproduction 63 1490-1496. (doi:10.1095/ biolreprod63.5.1490)

Schlatt S, Kim SS \& Gosden R 2002 Spermatogenesis and steroidogenesis in mouse, hamster and monkey testicular tissue after cryopreservation and heterotopic grafting to castrated hosts. Reproduction 124 339-346. (doi:10.1530/rep.0.1240339)

Schlatt S, Honaramooz A, Ehmcke J, Goebell PJ, Rubben H, Dhir R, Dobrinski I \& Patrizio P 2006 Limited survival of adult human testicular tissue as ectopic xenograft. Human Reproduction 21 384-389. (doi:10.1093/humrep/dei352)

Schlatt S, Gassei K, Westernstroer B \& Ehmcke J 2010 Modulating testicular mass in xenografting: a model to explore testis development and endocrine function. Endocrinology 151 4018-4023. (doi:10.1210/en. 2010-0415)

Shan LX \& Hardy MP 1992 Developmental changes in levels of luteinizing hormone receptor and androgen receptor in rat Leydig cells. Endocrinology 131 1107-1114. (doi:10.1210/endo.131.3.1505454)

Snedaker AK, Honaramooz A \& Dobrinski I 2004 A game of cat and mouse: xenografting of testis tissue from domestic kittens results in complete cat spermatogenesis in a mouse host. Journal of Andrology 25 926-930. (doi:10.1002/j.1939-4640.2004.tb03163.x)

Sridharan S, Simon L, Meling DD, Cyr DG, Gutstein DE, Fishman GI, Guillou F \& Cooke PS 2007 Proliferation of adult Sertoli cells following conditional knockout of the Gap junctional protein GJA1 (connexin 43) in mice. Biology of Reproduction 76 804-812. (doi:10.1095/biolreprod. 106.059212)

Teerds KJ, Rijntjes E, Veldhuizen-Tsoerkan MB, Rommerts FF \& de BoerBrouwer M 2007 The development of rat Leydig cell progenitors in vitro: how essential is luteinising hormone? Journal of Endocrinology 194 579-593. (doi:10.1677/JOE-06-0084)

Ward CM, Barrow KM \& Stern PL 2004 Significant variations in differentiation properties between independent mouse ES cell lines cultured under defined conditions. Experimental Cell Research 293 229-238. (doi:10.1016/j.yexcr.2003.10.017)

Western PS, van den Bergen JA, Miles DC \& Sinclair AH 2010 Male fetal germ cell differentiation involves complex repression of the regulatory network controlling pluripotency. FASEB Journal 24 3026-3035. (doi:10.1096/fj.09-151555)

Wistuba J, Luetjens CM, Wesselmann R, Nieschlag E, Simoni M \& Schlatt S 2006 Meiosis in autologous ectopic transplants of immature testicular tissue grafted to Callithrix jacchus. Biology of Reproduction 74 706-713. (doi:10.1095/biolreprod.105.048793)

Wykes SM, Nelson JE, Visscher DW, Djakiew D \& Krawetz SA 1995 Coordinate expression of the PRM1, PRM2, and TNP2 multigene locus in human testis. DNA and Cell Biology 14 155-161. (doi:10.1089/dna. 1995.14.155)

Yao HH, Whoriskey W \& Capel B 2002 Desert hedgehog/Patched 1 signaling specifies fetal Leydig cell fate in testis organogenesis. Genes and Development 16 1433-1440. (doi:10.1101/gad.981202)

Yelick PC, Kozak C, Kwon YK, Seldin MF \& Hecht NB 1991 The mouse transition protein 1 gene contains a B1 repetitive element and is located on chromosome 1. Genomics 11 687-694. (doi:10.1016/08887543(91)90076-Q)

Zhao M, Shirley CR, Mounsey S \& Meistrich ML 2004 Nucleoprotein transitions during spermiogenesis in mice with transition nuclear protein Tnp1 and Tnp2 mutations. Biology of Reproduction 71 1016-1025. (doi:10.1095/biolreprod.104.028191)

Received 30 October 2014

First decision 17 November 2014

Revised manuscript received 9 December 2014

Accepted 16 December 2014 